\title{
Associative asymmetry in paired associate to serial transfer
}

DAVID L. HORTON ${ }^{2}$ AND DAVID E. GROVER UNIVERSITY OF KENTUCKY

This experiment involved transfer from a double function paired associate list to either a forward $(S-R)$ or backward $(R-S)$ list derived from the serial list. In contrast to a control group the results indicated significant transfer in the $S-R$ condition but not in the $R-S$ condition. Although the presence of strong interference effects in the learning of a double function list makes it impossible to offer an unambiguous interpretation of these results, it does seem clear that the principle of associative symmetry cannot apply to both acquisition and unlearning.

Battig and Koppenaal (1965) recently demonstrated asymmetry of S-R vs R-S recall following the learning of a double function paired associate (PA) list. The authors noted that the use of a double function list has the unique advantage of maintaining equal familiarity with the items-an equality which rarely obtains and which has created major problems in the interpretation of research dealing with the associative symmetry issue (cf. Ekstrand, 1966).

The present experiment constitutes an attempt to extend the Battig and Koppenaal findings to a situation which involves the utilization of associations rather than the recall of associations. A possible difficulty with the recall procedure is that the Ss were given only one opportunity to utilize the previously acquired associations and any carry over of the S-R set established during PA learning would necessarily favor $S-R$ recall. It was reasoned that transfer to a multi-trial learning task might reduce or eliminate this problem. The specific task employed in the present study involved transfer from a double function PA list to a serial list. Previous research has shown positive transfer-at least for S-R associationsin this situation (cf. Jenson, 1962).

Method

Two experimental conditions and a control condition were employed in the experiment. The two experimental groups learned the same double function PA list to a criterion of one errorless trial and were transferred to either a forward (Group F) or backward (Group B) serial list (12 items) which was derived from the PA list. The control group (Group C) learned a different double function PA list and was transferred to the same serial lists. Half of the Ss in Group $C$ learned the torward serial list and the other half learned the backward serial list. Thirty introductory psychology students served as Ss. The Ss were randomly assigned to conditions in accordance with their order of appearance for the experiment.
The PA lists were composed of 12 pairs of three letter words (12 words). The experimental groups learned a PA list composed of the 10 words used by Battig and Koppenaal plus two additional words. The control group learned a different but comparable 12 pair list. The items were typed in pica capitals and presented on a Lafayette memory drum at a $2 \mathrm{sec} / 2 \mathrm{sec}$ rate with a 2 sec intertrial interval. Three random orders of the PA lists were employed to prevent serial learning of the responses. The serial lists ( $S-R$ and $R-S$ ) were presented at a 2 sec rate with a 2 sec intertrial interval. The serial list was learned to a criterion of one errorless trial.

\section{Resulits}

The mean number of trials to criterion on the PA lists was 24.2 for Group F, 25.8 for Group B, and 22.1 for Group C. Analysis of variance showed that these values did not differ significantly $(F=1.19, \mathrm{df}=2 / 27)$. Thus the Groups appear to be comparable in learning ability.

Performance on the serial list was analyzed for both number of correct responses on the first two trials (the fastest $S$ learned this list in two trials) and number of trials to criterion. The mean number of correct anticipations for Groups F, B, and $\mathrm{C}$ was 13.9, 6.8, and 7.5 respectively. Analysis of variance indicated that the means differed significantly $(F=10.71, d f=2 / 27, p<$ $.001)$. Individual comparisons showed that Group $F$ was superior to Groups $B(t=3.78, d f=18)$ and $C(t=3.60$, $\mathrm{df}=18$ ) at the 1 per cent level. Groups $B$ and $C$ did not differ significantly $(t=.51, d f=18)$.

The mean number of trials to criterion was 5.0 for Group F, 10.6 for Group B, and 8.9 for Group C. These values also differed significantly $(F=11.17, d f=2 / 27$, $p<.001)$ with Group $F$ being superior to Groups $B(t=$ 5.19, $d f=18)$ and $C(t=3.22, d f=18)$ at the 1 per cent level. Again, Groups B and $C$ did notdiffer significantly $(t=1.27, d f=18)$.

\section{Discussion}

The results obtained here are in good agreement with the findings reported by Battig and Koppenaal (1965). Transfer was obtained in the S-R condition on both the early trials of serial learning and trials to criterion. However, no indication of transfer was obtained in the $\mathrm{R}-\mathrm{S}$ condition with either measure. Therefore, asymmetry clearly has been demonstrated al though the interpretation of this finding is not immediately clear.

Perhaps the most obvious view of these findings is to conclude that asymmetry is the rule and symmetry is obtained only under very special conditions. This interpretation certainly is consistent with most of the research findings concerned with the symmetry issue 
(cf. Ekstrand, 1966). However, there are two aspects of associative symmetry that may be involved in the present study-acquisition and unlearning. Ekstrand (1966) has suggested that during the learning of a double function list (A-B, B-C, C-D etc.) the backward associations (B-A, C-B, D-C etc.) may be unlearned although the forward associations are not and that this asymmetry in unlearning is what is actually responsible for differential $S-R$ and $R-S$ recall or transfer. If this is the case the symmetry position can be maintained for acquisition (i.e., the weak law of symmetry) but not for unlearning or extinction (i.e., the strong law of symmetry). That is, it can be argued that during PA learning S-R and R-S associations of equal strength are established but subsequent interference effects may differentially weaken these associations. Although further research will be needed to enable a choice to be made between these alternatives it is clear that the principle of associative symmetry cannot apply to both acquisition and unlearning-if, in fact, it applies in either case.

References

BATTIG, W. F., \& KOPPENAAL, R: J. Associative symmetry in S-R vs. R-S recall of double-function lists. Psychol. Repts., 1965, 16, 287-293.

EKSTRAND, B. R. Backward associations. Psychol. Bull, 1966, 65, $50-64$.

JENSEN, A. R. Transfer between paired-associate and serial learning. J. verb. Learn. verb. Behav., 1962, 1, 269-280.

Notes

1. This research was supported by National Science Foundation Grant GB 3722.

2. Now at the University of Maryland. error as would be an item which had been isolated by color. It is hypothesized that the more the isolating stimulus is an integral part of the to-be-isolated list item, then the greater is the tendency for the isolated list item to interfere with performance as an overt intralist intrusion; since (inversely) the less the isolating stimulus is embedded into the to-beisolated list item, the less is S's tendency to anticipate the isolating stimulus by emitting the isolated list item. It is thus suggested that isolation by shock may have led to facllitated total list learning in Group SI because overt intralist errors may have been grossly attenuated, in turn allowing for the spread of signal value of the shocked item to its surrounding items.

Wishner, Shipley, \& Hurvich (1957) obtained results similar to those of Raskin et al. When each half of a list was differentiated by differences in type-size and color, learning was facilitated in comparison to acquisition of a homogeneous, nondifferentiated list. (The "change-point" around which the greatest intralist facilitation occurrred could not be anticipated per se as a to-be-learned response.) Wishner et al attributed this facilitation to not only list differentiation but also to Ss' set, produced by instructions to learn several lists which would differ in color and type. Since Ss in the Raskin et al ex- periment were informed of the presence of the auxiliary shock stimulus in instructions prior to acquisition, it is possible that shock served to bisect the list into two consecutive 6-item lists: One list was initiated by the termination of the intertrial interval (which represents absence of an item and is not overtly anticipated), and the other by the shock (an extralist stimulus which, likewise, is not anticipated overtly, per se, as a to-be-learned response). To eliminate this possibility, it is suggested that the arousing influence of an evoked orienting reflex upon total list performance could be better tested by varying the serial position at which shock is presented from trial to trial.

\section{References}

NEWMAN, S. E., \& SALTZ, E. Isolation effects: Stimulus and response generalization as explanatory concepts. J. exp. Psychol, 1958, 55, 467-472.

RASKIN, D. C., HATTLE, M., \& RUBEL, E. W. The effects of electric shock isolation in serial learning. Psychon. Sci, 1967, 8, 413-414.

WALLACE, W. P. Review of the historical, empirical, and theoretical status of the von Restorff phenomenon. Psychol Bull., 1965, 63, $410-424$.

WISHNER, J., SHIPLEY, T. E., JR., \& HURVICH, M. S. The serialposition curve as a function of organization. Amer. J. Psychol., $1957,70,258-262$. 